\title{
Modificações na matriz de um Argissolo Amarelo Coeso sob diferentes sistemas de manejo com cana-de-açúcar ${ }^{1}$
}

\author{
Apolino J. N. da Silva ${ }^{2} \&$ Mário S. V. Cabeda ${ }^{3}$
}

\begin{abstract}
RESUMO
Os sistemas de manejo com cana-de-açúcar em solos de tabuleiros costeiros podem causar alterações importantes na matriz do solo. Foram estudados os efeitos de diferentes sistemas de manejo com cana-de-açúcar na organização da matriz de um Argissolo Amarelo Coeso, na usina Triunfo, Estado de Alagoas. Os sistemas de manejo consistiram de uma área não irrigada, uma área irrigada, uma com aplicação de vinhaça e uma sob floresta nativa como condição original. Amostras foram retiradas de cada área a 0-0,2, 0,2-0,4 e 0,4-0,8 m de profundidade para determinar as alterações na estrutura do solo, no sistema de poros e no arranjamento de partículas dos solos cultivados com cana-de-açúcar, em relação ao solo da mata. Os solos cultivados apresentaram associação da porosidade natural com poros aplanados e um arranjamento mais compacto das partículas na matriz solo. Nos agregados dos solos cultivados constatou-se um aspecto maciço e orientação de partículas de argila, em relação ao solo da mata.
\end{abstract}

Palavras-chave: compactação, estrutura, óxidos, tabuleiros costeiros

\section{Modifications in the matrix of a Cohesive Yellow Argisol under different management systems with sugar cane}

\begin{abstract}
The management systems with sugarcane in soils of Coastal Tablelands can cause important alterations in the soil matrix. The effects of different management systems with sugar cane in the organization of the matrix of a Cohesive Yellow Argisol, in the Triunfo Sugar Cane Mill in State of Alagoas, as compared to a virgin soil were studied. The management systems consisted of irrigated area, not irrigated, with vinasse application and an area under native forest as original condition. Samples were collected from each site at 0-0.2, 0.2-0.4 and 0.4-0.8 m depths to determine the alterations in the soil structure, in pore system and in the arrangement of particles of the soils cultivated with sugarcane, in relation to the soil under native forest. The cultivated soils presented an association of natural porosity with planar pores resultant of the cultivation and a more compact arrangement of particles in the soil matrix. In the aggregates of the cultivated soils a massive aspect and orientation of clay particle was verified in relation to the aggregates of the soil under native forest.
\end{abstract}

Key words: compaction, soil structure, oxides, coastal tablelands 


\section{INTRODUÇÃO}

O cultivo do solo sob diversos sistemas de manejo tem provocado mudanças nas propriedades físicas e morfológicas decorrentes da compactação do solo (Corsini et al., 1986; Hill \& Mesa-Montalvo, 1990). Apesar das mudanças nessas propriedades poderem ser mensuradas numa macroescala, por meio de determinação de porosidade e densidade do solo, geralmente elas são conseqüências de alterações na estrutura do solo em uma microescala, com alterações na organização interna da matriz do solo no que diz respeito à forma e orientação de poros ou arranjo das partículas primárias e secundárias do solo (Pagliai, 1987; Chartres \& Norton, 1994; Drees et al., 1994).

As modificações na estrutura do solo devido às atividades de cultivo refletem alterações no arranjamento das partículas na matriz do solo. Oliveira et al. (2000) observaram diferenças na organização das unidades estruturais e texturais do solo e na forma dos poros através de microscopia em lâminas delgadas. Os autores verificaram que, em Cambissolos não cultivados, os indícios de atividades da fauna são mais evidentes, com presença de estruturas fecais e bioporos com grande individualização dos agregados. Nos solos cultivados, a matriz do solo apresentou um empacotamento mais denso de suas partículas, com maior presença de poros tipo fendas, distribuídos paralelos à superfície do solo, evidenciando a ocorrência da compressão do solo devido ao tráfego de máquinas agrícolas. A fragmentação de nódulos e concreções de ferro e manganês também foram observadas nas áreas cultivadas, sendo também indicadores do efeito de máquinas no preparo do solo.

As alterações nas propriedades físicas do solo devido aos efeitos do cultivo contínuo podem ser melhor entendidas através de observações das mudanças na organização interna da estrutura do solo. Marsili et al. (1998) verificaram que a compactação em solo submetido ao tráfego de máquinas reduziu a macroporosidade e modificou a distribuição de tamanho dos poros em relação ao solo não compactado. Os autores enfatizaram que a redução na condutividade hidráulica do solo está associada à redução dos poros alongados na direção vertical e ao aumento destes na direção horizontal, paralelos à superfície do solo. Segundo os autores, poros alongados verticalmente são importantes pois afetam diretamente o crescimento das plantas por promover a penetração de raízes e a transmissão vertical de água e gases no solo.

Os diferentes sistemas de cultivo também podem promover mudanças importantes na organização na matriz do solo. Vandenbygaart et al. (1999) observaram alterações na organização das partículas na matriz do solo devido à mudança do sistema preparo convencional para o sistema plantio direto. Na área sob preparo convencional, os autores observaram a formação de uma crosta superficial, com orientação de argila e poucos agregados distintos na matriz do solo. Após mudança para o sistema de plantio direto por 4 anos, poros alongados e paralelos à superfície do solo ainda são evidentes, e a matriz ainda apresenta um aspecto maciço, com predominância de microporos; após
11 anos da implantação do plantio direto, a estrutura mostrou-se muito porosa, com poros interconectados e boa agregação do solo, refletindo o aumento da matéria orgânica e grande atividade microbiana.

Além de mudanças na porosidade e arranjamento das unidades estruturais e texturais do solo, outra conseqüência do cultivo diz respeito a seus efeitos na movimentação de partículas para os sub-horizontes do solo. Esse efeito pode ter origem nas mudanças químicas provocadas pelos diversos sistemas de manejo, como o desequilíbrio de cátions e alterações no $\mathrm{pH}$ do solo, podendo promover a dispersão de argila que, associada às condições de chuva e/ou irrigação, eluviam e bloqueiam os poros (Helalia et al., 1988; Silva, 2003).

Dantas et al. (1998) verificaram feições de argila iluvial nos horizontes subsuperficiais de Podzólicos Amarelos cultivados com manga, constatando revestimento de argila iluvial sobre os grãos de quartzo na fração grosseira do solo, formando os típicos revestimentos em cúpulas. Tais revestimentos se dispõem aproximadamente paralelos à superfície do solo e contribuem para a diminuição da permeabilidade dos sub-horizontes. Nas lâminas delgadas da área não cultivada, os autores constataram a presença de porosidade específica (bioporos), desenvolvida pela maior atividade biológica, além de uma maior frouxidão no empacotamento dos grãos, refletindo a menor compactação do solo.

A cana-de-açúcar exerce papel importante na economia do Nordeste do Brasil, e os efeitos de seu cultivo contínuo na degradação das propriedades físicas e químicas do solo têm sido estudados por alguns autores (Silva \& Ribeiro, 1992; Ball-Coelho et al., 1993). Poucos trabalhos, no entanto, têm estudado as alterações micromorfológicas na matriz dos solos cultivados com cana-de-açúcar (Silva et al., 1998).

As mudanças nos atributos físicos do solo provocadas pelos diferentes sistemas de manejo e seus reflexos na estrutura do solo podem ser estudados em associação com as mudanças na organização interna da matriz do solo, referente ao rearranjo das partículas e unidades estruturais, porosidade e estrutura do solo após o cultivo. Isto é importante para o melhor entendimento das mudanças nas propriedades físicas que ocorrem em decorrência do uso agrícola.

Objetivou-se com este trabalho verificar o efeito de sistemas de manejo com cana-de-açúcar na organização e arranjo das partículas e unidades estruturais, distribuição e forma dos poros e na estrutura de um Argissolo Amarelo Coeso de tabuleiro costeiro.

\section{MATERIAL E MÉTODOS}

O estudo foi realizado em áreas da Usina Triunfo AgroIndustrial, localizada no município de Boca da Mata, no Estado de Alagoas. O solo estudado foi classificado como um Argissolo Amarelo Coeso latossólico de textura média/argilosa, originado do grupo Barreiras, formado por sedimentos areno-argilosos e constituídos, principalmente, por quartzo na fração areia e na fração argila com predomínio de caulinita, com baixos teores de óxidos de ferro, principalmente 
goetita (Jacomine et al., 1975). A área tem clima tropical chuvoso com verão seco, precipitação média anual de 1200 mm, com período de maior precipitação nos meses de abril a julho (Nimer, 1989), temperatura média anual de $29{ }^{\circ} \mathrm{C}$ e relevo predominantemente plano e suave ondulado, característicos da região de Tabuleiros Costeiros (Jacomine et al., 1975).

Foram estudados três diferentes sistemas de manejos com cana-de-açúcar (Saccharum officinarum L.), sendo um sob cultivo de sequeiro, um sob cultivo irrigado e uma área cultivada com aplicação de vinhaça. Estes manejos foram comparados entre si e em relação a uma testemunha absoluta, representada por solo virgem sob floresta subperenifólia. Todos os tratamentos estão situados numa mesma posição topográfica, em topo plano de platô costeiro, e os três sistemas de manejos com cana-de-açúcar são adotados há 25 anos consecutivos.

No plantio da cana planta, ou a cada 5-6 anos, quando da renovação do canavial, o preparo do solo nos três sistemas de manejo consiste em subsolagem realizada com subsolador marca Civemasa modelo STA 9P a uma profundidade de $35 \mathrm{~cm}$, seguida de duas gradagens com grade aradora de 18 discos de 30', trabalhando a uma profundidade de $25 \mathrm{~cm}$, com o objetivo de destruir a soqueira da cana. A abertura dos sulcos é feita com sulcador de 3 linhas a $25 \mathrm{~cm}$ de profundidade. No plantio, as canas são distribuídas manualmente no sulco, e na colheita, as canas são cortadas manualmente e carregadas para caminhão com carregadeira convencional Ford 5630. Em todas as áreas cultivadas a cana-de-açúcar é queimada antes da colheita.

Na área com sistema de manejo com vinhaça são aplicados anualmente $500 \mathrm{~m}^{3} \mathrm{ha}^{-1}$ de vinhaça por safra da cultura, sendo a aplicação feita por aspersor com vazão de $150 \mathrm{~m}^{3} \mathrm{~h}^{-1}$. Também são administrados $20 \mathrm{Mg} \mathrm{ha}^{-1}$ de torta de filtro na renovação do canavial.

No sistema de manejo irrigado é aplicada uma lâmina de $120 \mathrm{~mm}$ anual de água por safra da cultura, através de aspersor com vazão de $100 \mathrm{~m}^{3} \mathrm{~h}^{-1}$. A área com regime de sequeiro nunca foi irrigada nem recebeu vinhaça. Nos sistemas de manejo irrigado e de sequeiro as adubações são feitas de acordo com a análise do solo, sendo geralmente administradas 60 , 90 e $120 \mathrm{~kg} \mathrm{ha}^{-1}$ de $\mathrm{N}, \mathrm{P}_{2} \mathrm{O}_{5}$ e $\mathrm{K}_{2} \mathrm{O}$, respectivamente e $20 \mathrm{Mg} \mathrm{ha}^{-1}$ de torta de filtro na cana planta. Na cana soca são aplicados 60 e $100 \mathrm{~kg} \mathrm{ha}^{-1}$ de $\mathrm{P}_{2} \mathrm{O}_{5}$ e $\mathrm{K}_{2} \mathrm{O}$, respectivamente.

A amostragem foi realizada ao acaso nas áreas com os diferentes sistemas de uso e manejo, sendo coletadas amostras nas camadas de 0-0,2, 0,2-0,4 e 0,4-0,8 m. Foram coletadas amostras indeformadas com auxílio de caixas de Kubiena para posterior confecção das lâminas delgadas. Para padronizar a amostragem, as amostras foram coletadas a $30 \mathrm{~cm}$ das linhas de plantio da cana-de-açúcar e na região central de cada horizonte (metade da espessura), sendo devidamente etiquetadas com identificação e orientação.

A impregnação das amostras com resina foi feita segundo metodologia descrita por Jongerius \& Heintzberger (1963). As amostras indeformadas foram inicialmente secas ao ar, depois levadas à estufa a $40^{\circ} \mathrm{C}$ para eliminar o exces- so de umidade. Posteriormente, foram impregnadas sob vácuo com mistura composta de resina poliéster Resapol T208, monômero de estireno (solvente) e peróxido de metil-etilcetona (catalisador).

Após a impregnação as amostras foram desbastadas utilizando máquina de corte com disco de diamante. Os blocos de solo formados foram colados em lâminas de vidro com a mistura Araldite Epoxi CY248 mais endurecedor HY956, e posteriormente foram submetidos a polimentos sucessivos em sistema rotativo marca Montasupal, com abrasivos de carbeto de silício com granulações $n^{0} 320,600$ e 1000, até ficarem com espessura final entre $30-35 \mu \mathrm{m}$. A espessura final das lâminas foi verificada com paquímetro, associado à observação das cores de interferência dos minerais nas lâminas, com auxílio do microscópio petrográfico. A limpeza das lâminas delgadas foi realizada em cubas de ultra-som conforme Murphy (1986).

As lâminas delgadas foram estudadas com microscópio petrográfico de luz transmitida, marca Carl Zeiss Jeneval, para observações na organização da matriz do solo no que diz respeito à geometria de poros, microestrutura e arranjamento das unidades estruturais e texturais dos solos nos sistemas de manejo estudados. As descrições micromorfológicas das lâminas foram feitas segundo os conceitos de Bullock et al. (1985). As micrografias nas lâminas delgadas foram obtidas com câmara fotográfica Canon Prima Super 105, com controle de exposição automático, utilizando filmes coloridos ISO 400, com magnificações entre 100 e 250 vezes.

Para observações de empacotamento de partículas argila e silte, amostras de agregados foram preparadas por metalização com o elemento ouro e foram analisadas com microscópio eletrônico de varredura (MEV) JEOL, modelo JSM 5800 , com voltagem de aceleração de $15 \mathrm{kV}$, sendo usadas magnificações variando de 200 a 10000 vezes. As micrografias foram obtidas por câmera Kodak Polaróide acoplada ao MEV, no Centro de Microscopia Eletrônica da UFRGS.

\section{RESULTADOS E DISCUSSÃO}

Os diferentes sistemas de manejo promoveram modificações nas propriedades micromorfológicas do solo no que diz respeito à microestrutura, tipo de porosidade e organização das partículas da matriz do solo.

A Figura 1 mostra as micrografias das lâminas delgadas obtidas com microscópio óptico na camada de 0-0,2 m dos tratamentos estudados. No solo sob mata nativa (Figura 1A), observa-se uma estrutura mais aberta, com presença de poros largos entre agregados e maior frouxidão no empacotamento dos grãos de areia e agregados na matriz do solo, havendo predomínio de poros do tipo empacotamento, onde os poros ocorrem entre os grãos de quartzo e agregados do solo (Brewer, 1976). Segundo Bullock et al. (1985), esses poros são muito interconectados, refletindo numa boa infiltração de água no solo.

Nos solos cultivados sob os sistemas de sequeiro, irrigado e vinhaça (Figura 1B, C e D, respectivamente), observa-se uma visível redução da porosidade, em relação ao 
A.
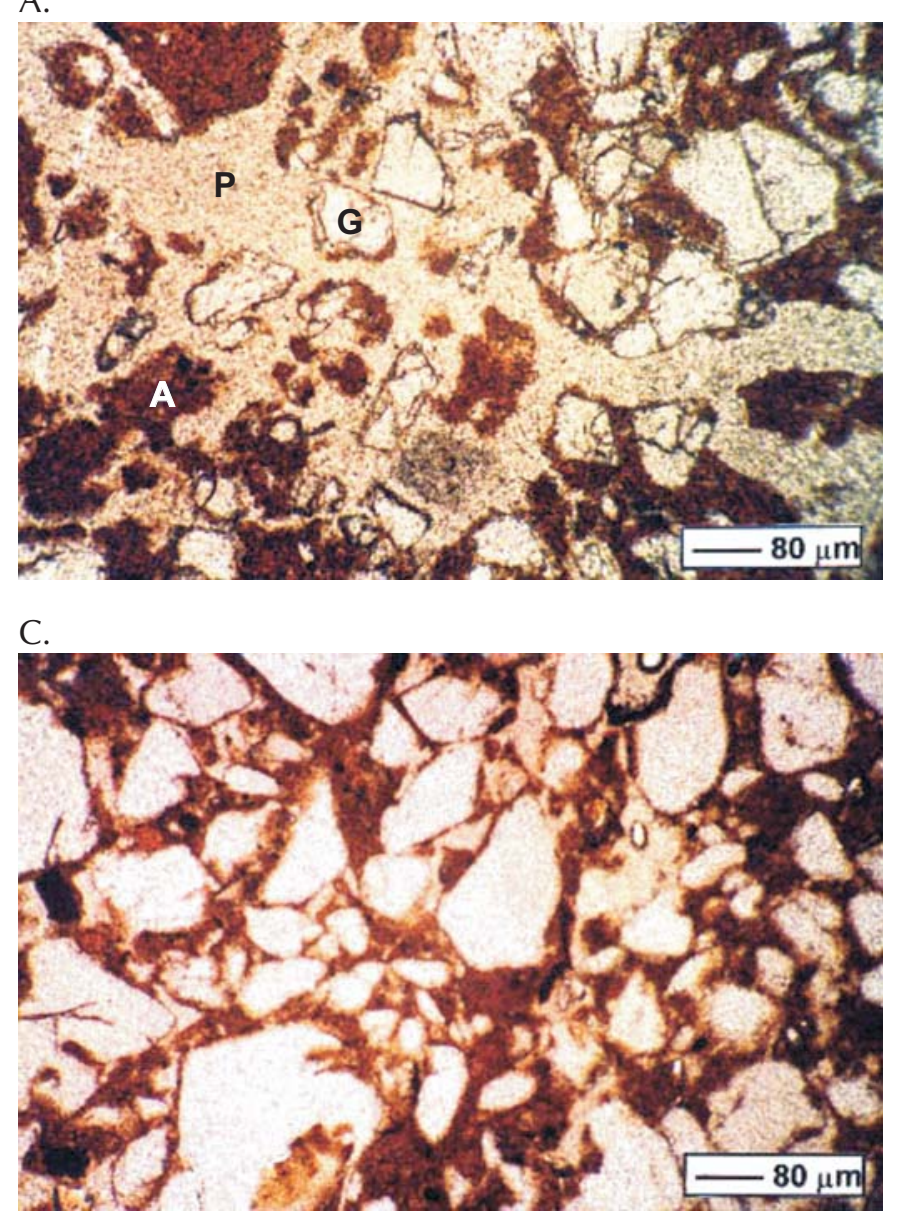

B.

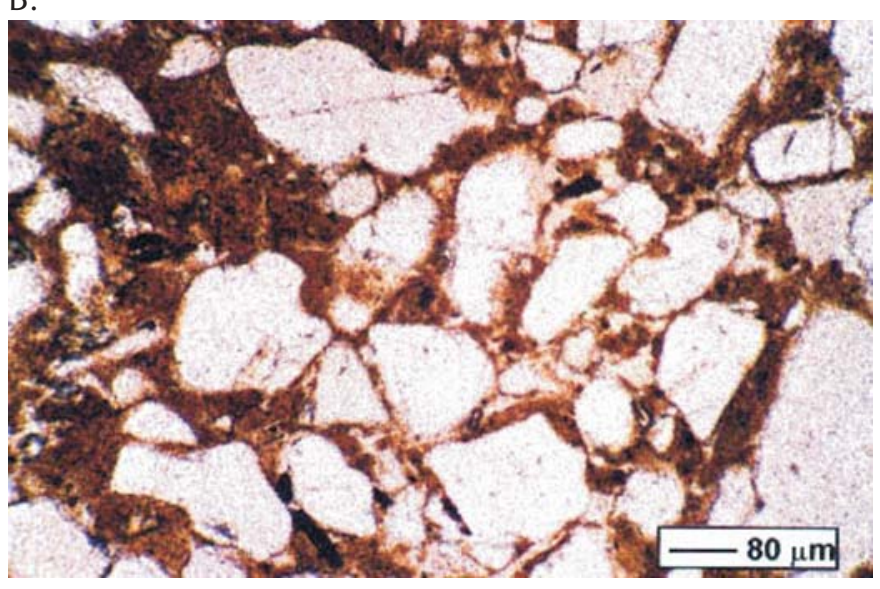

D.

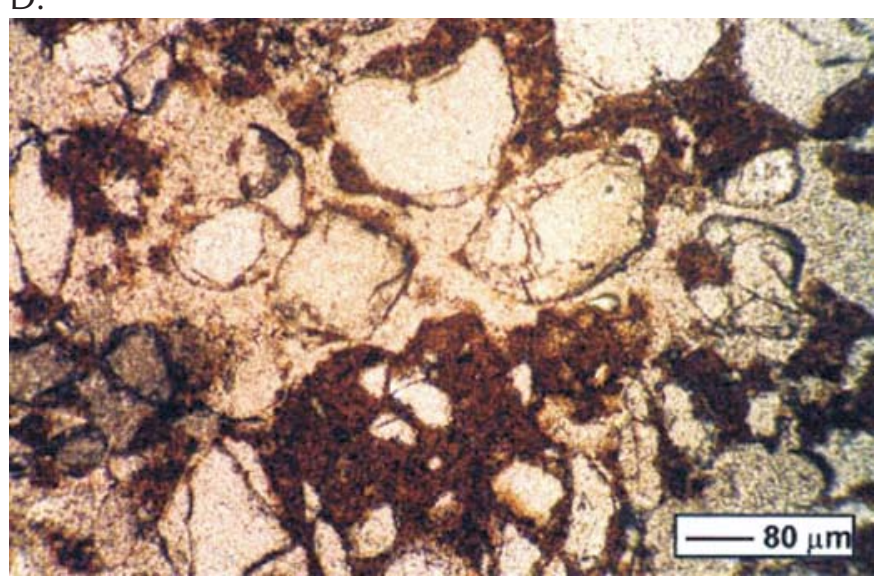

Figura 1. Micrografias obtidas com microscópio óptico, camada de 0-0,2 m. (A) solo sob mata nativa, porosidade elevada; (B) solo sob sequeiro, espaço poroso reduzido; $(C)$ solo irrigado, redução do espaço poroso; (D) solo com vinhaça, matriz com aspecto menos compactado. Legenda: $P$ - poro; $G$ - grão de areia; $\mathrm{A}$ - agregado

solo sob mata nativa, principalmente nos solos sob os sistemas de sequeiro e irrigado. Nota-se um maior entrosamento das partículas, onde as unidades menores preenchem os espaços entre as partículas maiores, observando-se nitidamente um maior número de pontos de contatos entre as partículas nos solos cultivados sob os sistemas sequeiro e irrigado (Figura 1B e C, respectivamente), em relação ao solo da mata. Na área com aplicação de vinhaça, a matriz do solo apresentou um arranjamento menos denso de suas partículas (Figura 1D), em relação aos solos sob os sistemas sequeiro e irrigado.

O rearranjamento das partículas na matriz do solo nas áreas cultivadas com cana-de-açúcar resultou num maior grau de compactação do solo, possivelmente como resultado das pressões externas exercidas nas atividades de cultivo. Esse empacotamento mais denso das partículas pode resultar numa maior capacidade de suporte de carga dos solos cultivados, pois o maior ajustamento das partículas e o maior número de pontos de contatos entre elas exercem na matriz do solo uma função esqueletal (Fitzpatrick, 1984), proporcionando uma maior resistência às pressões externas.

A Figura 2 mostra as micrografias das lâminas delgadas na camada de 0,2-0,4 m dos solos nos tratamentos estudados. O solo sob mata nativa apresenta uma estrutura granu- lar, com agregados arredondados exibindo uma forte pedalidade (Bullock et al., 1985), ou seja, rodeados por macroporos interconectados (Figura 2A). Este tipo de estrutura é resultado de sistemas com grande atividade biológica, e ao maior teor de matéria orgânica do solo (Brewer, 1976), o que é favorável à aeração e drenagem da água. Nos solos cultivados com cana-de-açúcar sob os sistemas de sequeiro, irrigado e vinhaça (Figura 2B, C e D, respectivamente), observa-se uma nítida redução da porosidade em relação ao solo da mata, bem como uma mudança na forma dos poros, com predominância de poros aplanados (Bullock et al., 1985). A mudança na estrutura é evidente nestes solos, observandose um predomínio de estrutura em blocos subangulares e angulares (Figura 2B e D), o que permite um maior ajustamento entre as faces dos agregados (Bullock et al., 1985). Segundo Lebert \& Horn (1991), a estrutura em blocos permite um maior entrosamento entre as unidades estruturais, resultando em maior coesão e atrito entre elas.

Nas três áreas cultivadas com cana-de-açúcar, constatouse também a presença de poros alongados, paralelos à superfície do solo, como verificado na Figura 2C. Este tipo de porosidade geralmente é resultado de processos de compressão do solo por máquinas agrícolas nas atividades de cultivo (Marsili et al., 1998; Vandenbygaart et al., 1999). 
A.

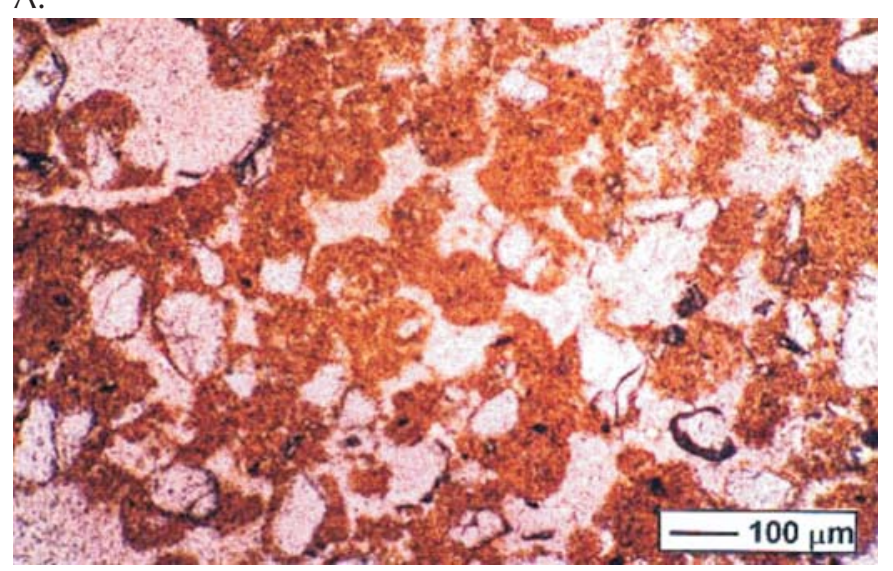

C.

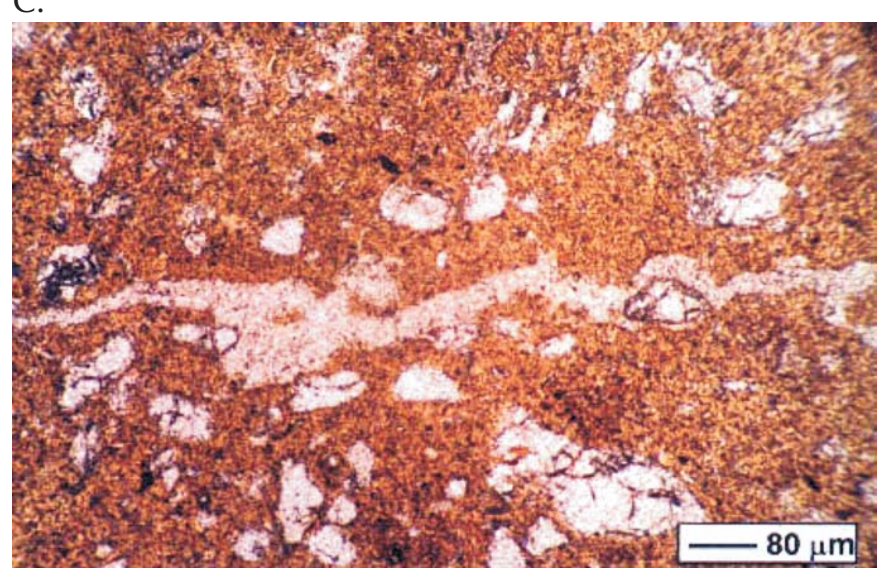

B.

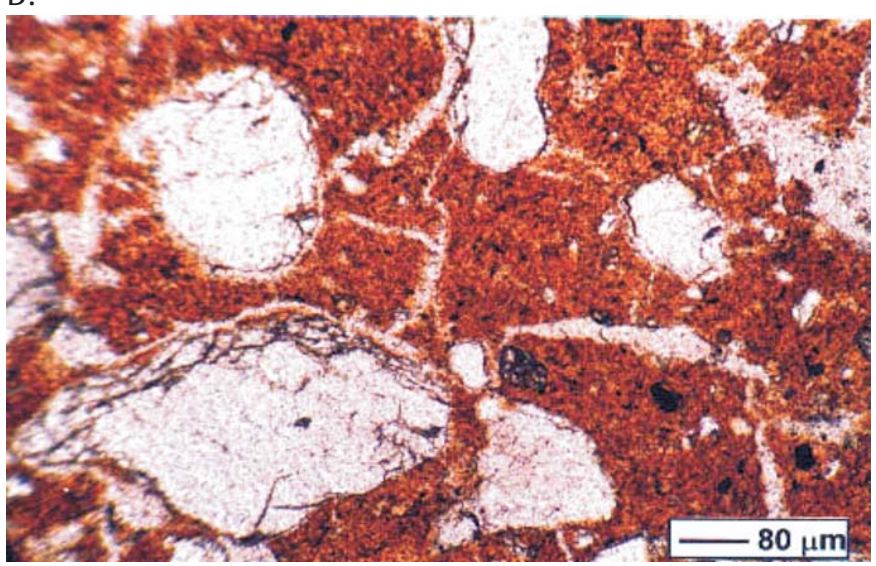

D.

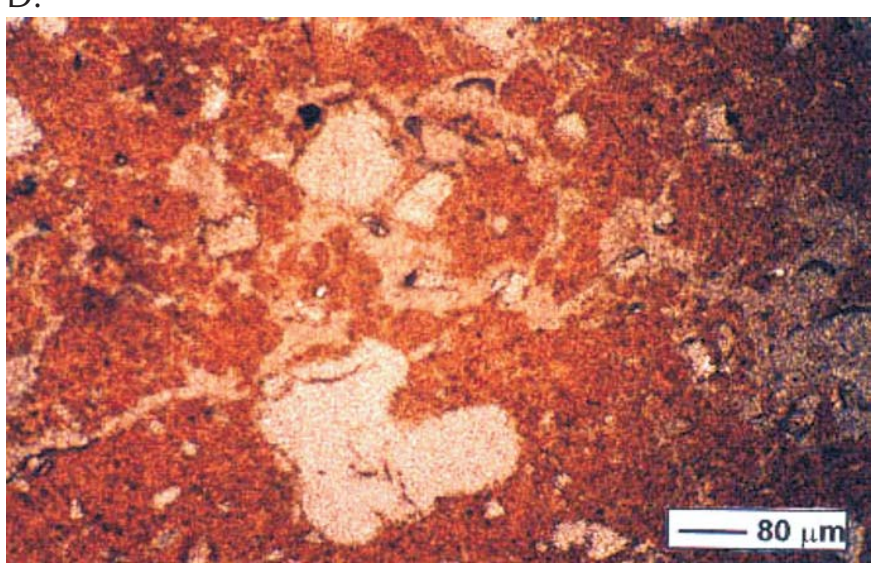

Figura 2. Micrografias obtidas com microscópio óptico, camada de 0,2-0,4 m. (A) solo da mata, estrutura granular; (B) solo sob sequeiro, estrutura em blocos angulares; (C) solo irrigado, matriz com aspecto maciço e poro alongado; (D) solo com vinhaça, estrutura em blocos subangulares

Na camada de 0,4-0,8 m, a organização matricial foi semelhante nas quatro áreas estudadas (Figura 3), onde os grãos de quartzo encontram-se totalmente embebidos num fundo matricial constituído pelas frações mais finas. Verificam-se, em geral, poucos macroporos visíveis, e predominância de microporos, dando a matriz do solo um aspecto maciço. Nas lâminas delgadas dos solos cultivados, no entanto, verificou-se a presença de poros tipo fissuras (Figura 3B e C), com aspecto descontínuo, o que geralmente reduz a drenagem da água no perfil do solo (Brewer, 1976). A presença deste tipo de poros na camada de 0,4-0,8 m das áreas cultivadas indica que os efeitos da compressão do solo nas atividades de cultivo atingiram esta camada. Resultados semelhantes foram verificados por Marsili et al. (1998) e Silva et al. (1998).

Além das mudanças na organização matricial, no que diz respeito ao arranjamento das partículas e geometria dos poros, verificaram-se alterações na qualidade dos agregados devido ao cultivo. A Figura 4A mostra a boa estrutura do solo da mata, onde os macroagregados $(\phi>250 \mu \mathrm{m})$ são rodeados por poros largos, evidenciando a maior macroporosidade neste solo, que facilita a aeração e infiltração da água no solo. Esses agregados são formados por agregados de menor tamanho ( $\phi$ entre 20-100 $\mu \mathrm{m}$ ), com um sistema de poros interligados entre si (Figura 4B). Segundo Tisdall \& Oades
(1982), os macroagregados resultam da associação de microagregados unidos por diversos agentes ligantes. Esses macroagregados quando formados em solos sob mata tem macroporos suficientes para promover a aeração, bem como microporos para a retenção de água para as plantas, enquanto os poros inter-agregados são largos para facilitar a infiltração da água.

Na Figura 4C, a matriz do solo mostra macroagregados com poucos poros visíveis e com formas mais arestadas, resultando em agregados com aspecto maciço, com predominância de microporos, o que geralmente reflete a ação de forças compressivas em solos cultivados (Dexter, 1988; Drees et al., 1994). Carpenedo \& Mielniczuk (1990) também verificaram agregados com forma mais arestadas e com aspecto adensado em solos cultivados, enfatizando que tais agregados são formados devido à compactação do solo.

Nas lâminas delgadas dos solos cultivados, observou-se também macroagregados com porosidade formada por fissuras, com aspecto de fratura, dividindo-se em agregados menores com formas mais angulares e pontiagudos (Figura 4D). De acordo com Drees et al. (1994), este tipo de porosidade dentro dos agregados geralmente reflete o início do fracionamento de um macroagregado em agregados menores devido às operações de cultivo do solo. Em solos cultivados, o processo de degradação física manifesta-se pela perda da 

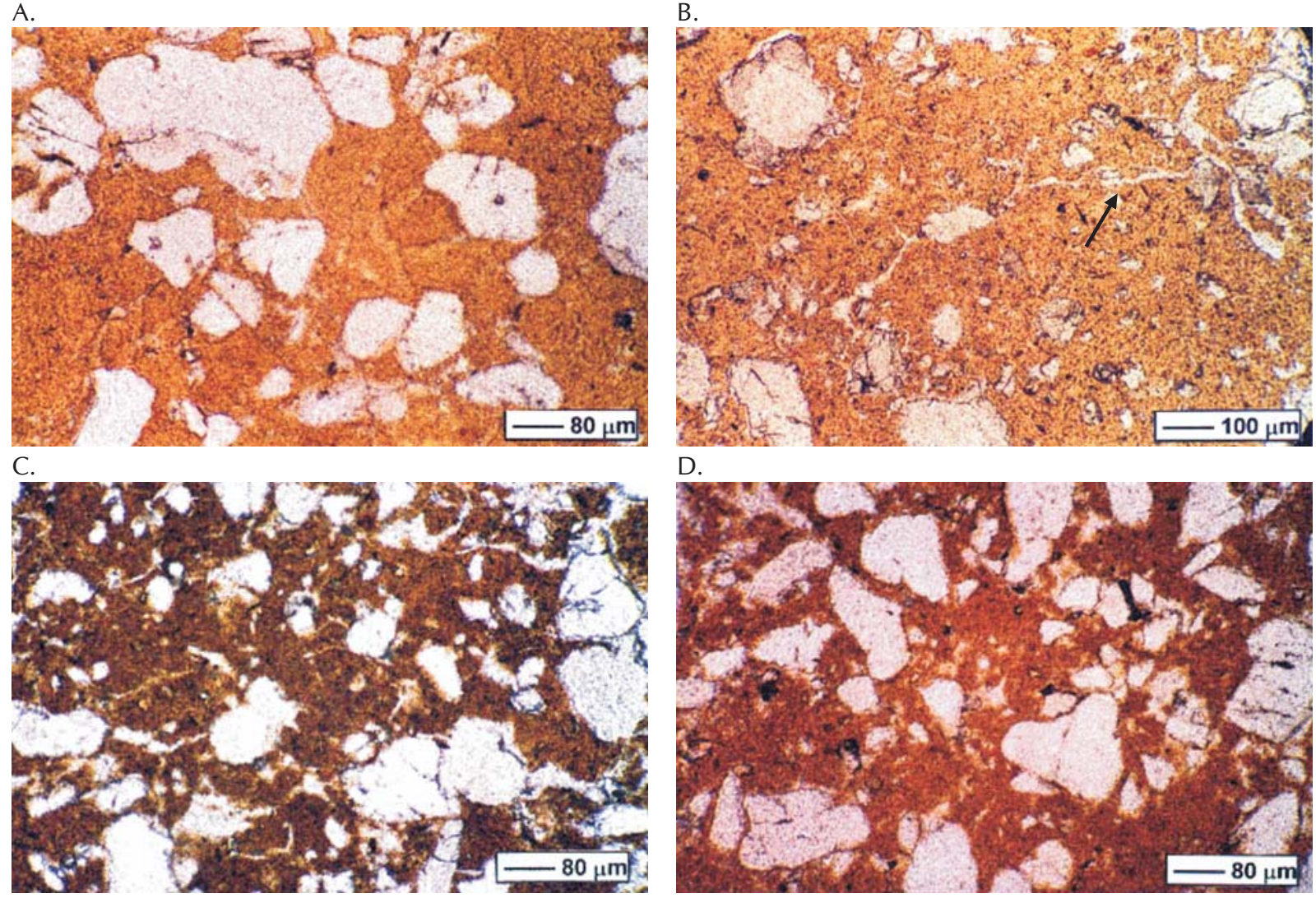

Figura 3. Micrografias obtidas com microscópio óptico, camada de 0,4-0,8 m. (A) solo da mata, matriz com aspecto maciço; (B) solo sob sequeiro, poros tipo fissuras (seta); (C) solo irrigado, poros fissurados; (D) solo com vinhaça; matriz com aspecto maciço
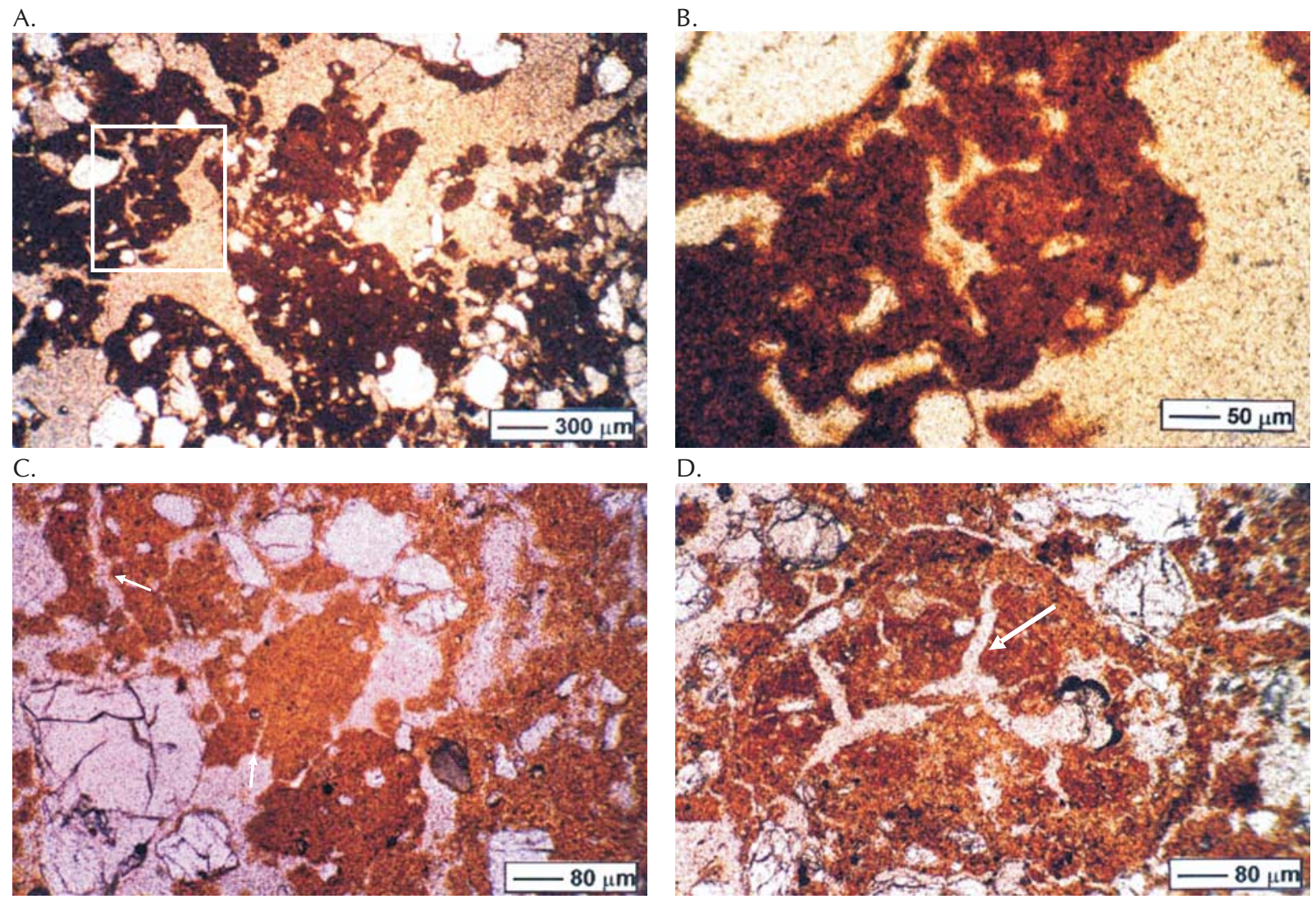

Figura 4. Micrografias obtidas com microscópio óptico, camada de 0-0,2 m. (A) solo da mata, macroagregados rodeados por poros largos; (B) ampliação da foto " $\mathrm{A}$ ", porosidade intra-agregados; (C) solo sob sequeiro, agregados com forma arestada e com fraturas (seta); (D) solo irrigado, macroagregado com fissuras (seta) 
qualidade da estrutura, podendo ocasionar crostas superficiais e camadas compactadas (Cabeda, 1984).

Nas áreas cultivadas com cana-de-açúcar, apesar do preparo do solo ser realizado a cada 5-6 anos, o intenso tráfego de máquinas anualmente nas operações de cultivo, adubação e principalmente colheita, provavelmente contribui para a compressão da matriz do solo e fragmentação dos agregados, contribuindo para a sua ruptura em agregados menores.

Observações feitas com o microscópio eletrônico de varredura mostram o arranjamento de partículas primárias em agregados dos solos (Figura 5), percebendo-se que o aspecto da porosidade dos agregados é um reflexo do arranjamento de partículas finas na matriz do solo. Os agregados do solo sob mata nativa mostram uma estrutura muito porosa com partículas de argila formando agregados tamanho silte, separados por superfície de fraqueza (Figura 5A). As partículas primárias são ligadas entre si devido à ação de agentes ligantes diversos
(Figura 5B), formando microagregados de diversos tamanhos na matriz do solo, que por sua vez dão origem aos macroagregados (Tisdall \& Oades, 1982).

Nos agregados das áreas sob os sistemas de sequeiro e vinhaça (Figuras 5C e D), verificam-se partículas tamanhos silte e argila com aspecto de orientação, ficando os agregados com aspecto maciço, com porosidade formada por diversas fissuras na superfície (Figura 5C), o que reflete o estado mais adensado dos agregados. Esse rearranjamento de partículas nos agregados provavelmente é resultado de compressão do solo nas atividades de cultivo. Segundo D’Agostini (1992), sob pressão compressiva, ocorre orientação das partículas nos agregados, tornando-os mais densos e coesos, e como conseqüência, mais resistentes à compressão. Este fenômeno também foi enfatizado por Utomo \& Dexter (1981).

Na camada superficial do solo sob mata nativa, a presença de porosidade específica (Figura 6A), ou seja, de bioporos (penetrações de raízes, atividades da fauna), é
A.

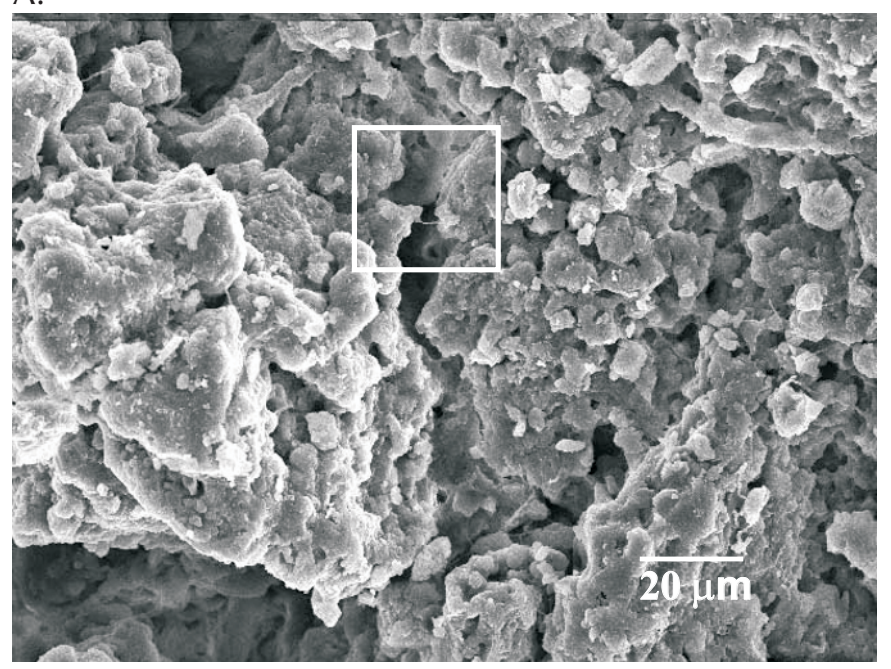

C.

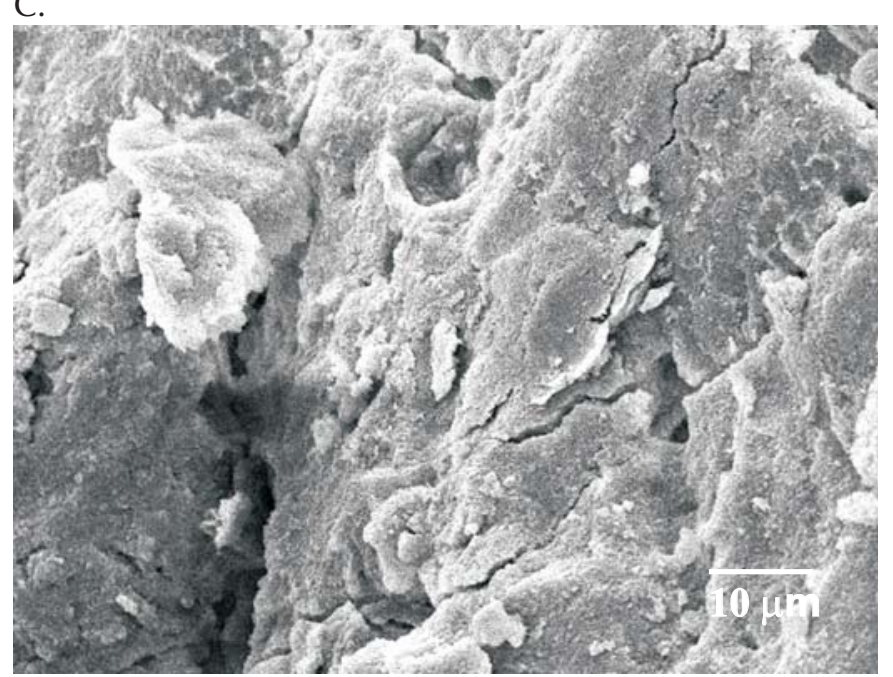

B.

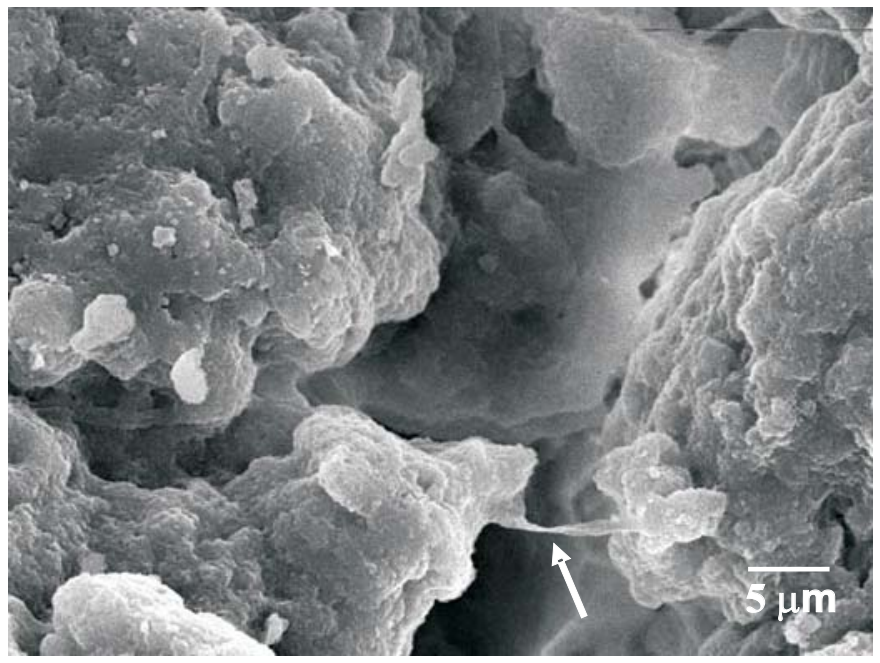

D.

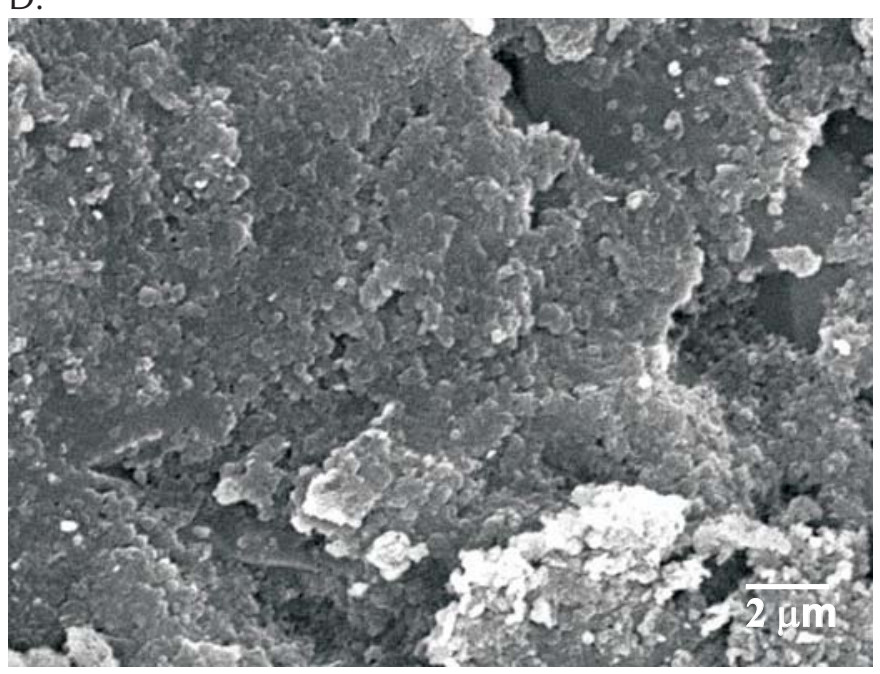

Figura 5. Micrografias obtidas com microscópio eletrônico de varredura (MEV), camada de 0-0,2 m. (A) solo da mata, estrutura porosa; (B) ampliação da foto " $\mathrm{A}$ ", agentes ligantes unindo partículas tamanhos silte e argila (seta); (C) solo sob sequeiro, agregado com orientação de partículas e aspecto adensado; (D) solo com vinhaça, agregado com orientação de partículas de argila 
A.

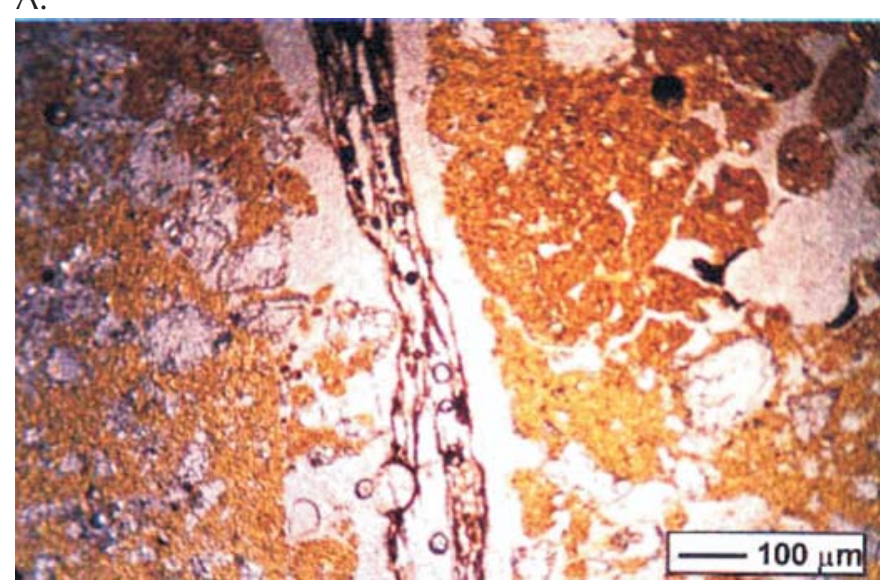

C.

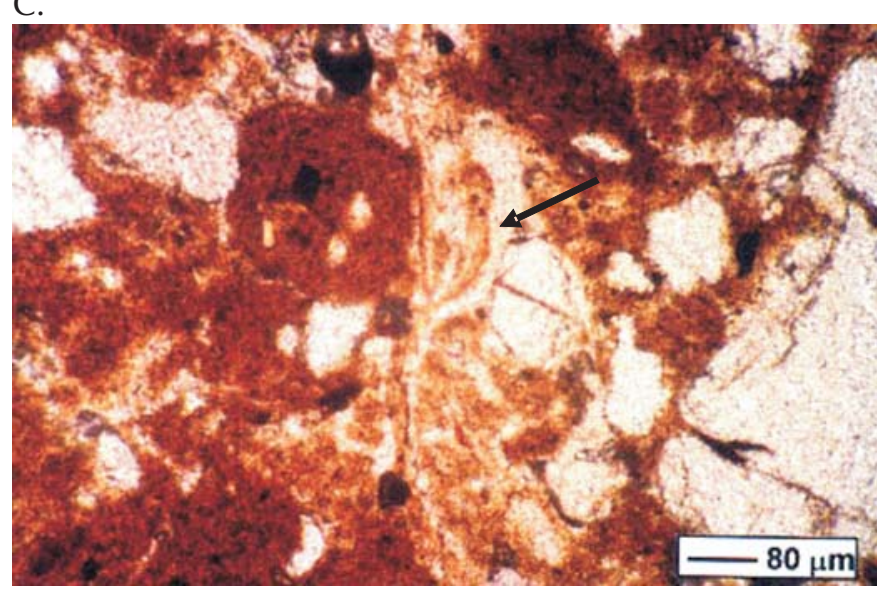

B.

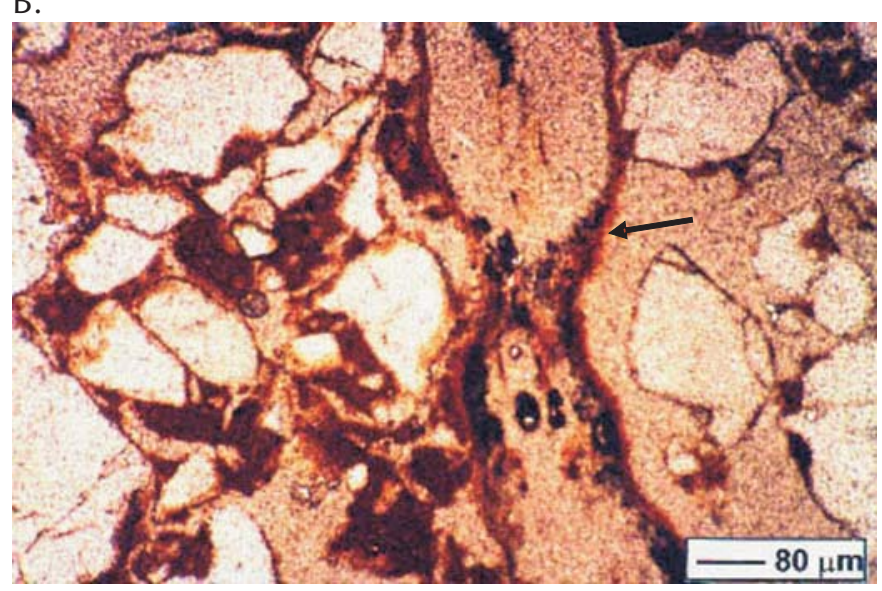

D.

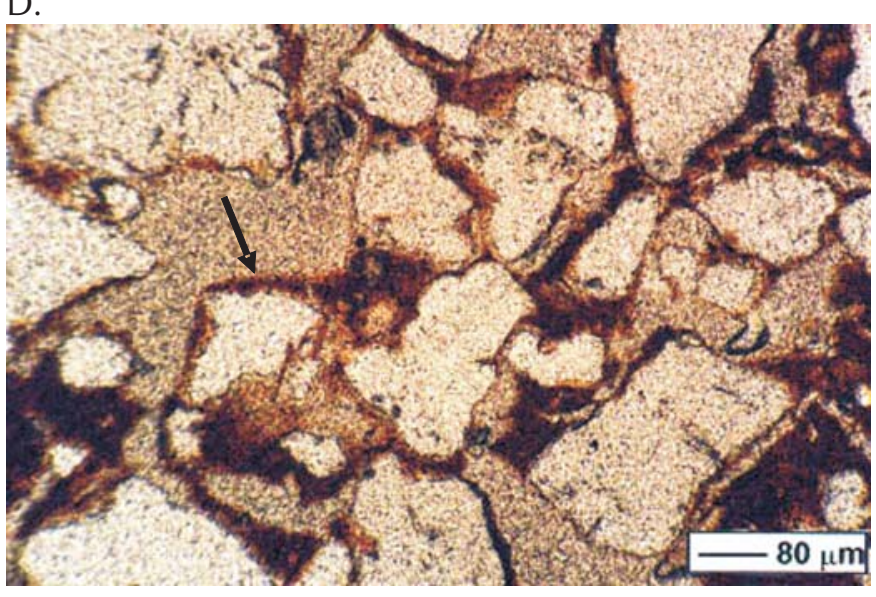

Figura 6. Micrografias obtidas com microscópio óptico. (A) solo da mata (0-0,2 m), bioporo; (B) solo sob sequeiro (0-0,2 m), fração mais fina do solo com aspecto típico de migração através de bioporo (seta); (C) solo irrigado (0-0,2 m), feição com aspecto de migração de partículas nos poros (seta); (D) solo com vinhaça $(0,2-0,4 \mathrm{~m})$, fração mais fina revestindo a superfície de grãos de areia (seta)

resultado da grande atividade biológica nas condições naturais do solo da mata.

Nas lâminas delgadas dos solos cultivados, no entanto, verificou-se a presença de poros com feições típicas que indicam a ocorrência de eluviação de materiais de granulometria mais fina através do perfil do solo (Figura 6B e C). Estas feições texturais se caracterizam por concentração de frações granulométricas mais fina (silte e argila), distinta do material adjacente (grãos de quartzo e agregados), com aspecto de escorrimento ou orientado, revestindo ou preenchendo as paredes dos poros, relacionando-as a mecanismos de transporte de partículas através do perfil do solo (Brewer, 1976; Cabrera-Martinez et al., 1989). As feições de argila iluvial também ocorrem através de revestimento dos grãos de quartzo na matriz do solo (Figura 6D) formando pontes de material mais fino entre eles (Brewer, 1976). Aspectos de iluviação de argila em solos cultivados também foram verificados por outros autores (Dantas et al., 1998; Silva et al., 1998). Penetrações de argila através de finos canais formados pelo avanço do crescimento de raízes de plantas com sistema radicular fasciculado também tem sido descrito na literatura (Cockroft et al., 1969) como um importante fenômeno de migração de argila.

\section{CONCLUSÕES}

1. O cultivo da cana-de-açúcar, independente do manejo adotado, modificou a organização da matriz do solo, resultando numa associação de poros em empacotamento, natural do solo da mata, com poros aplanados e fissuras, bem como um arranjamento mais compacto das partículas primárias e secundárias nos solos sob os sistemas sequeiro, irrigado e vinhaça, em relação ao solo da mata.

2. Os agregados dos solos cultivados com cana-de-açúcar apresentaram aspecto maciço, com orientação de partículas de argila, evidenciando um estado mais denso em relação aos agregados do solo sob mata nativa.

\section{AgRAdECIMENTOS}

Os autores agradecem à Usina Triunfo e aos engenheiros agrônomos Arnaldo Jugurta (Usina Triunfo) e José Fernandes Wanderley (UFRPE) pelo apoio logístico nas atividades de campo, e à professora Ruth Hinrichs do Departamento de Geociências da UFRGS, pelo auxílio nas observações com microscópio eletrônico de varredura. 


\section{LITERATURA CITADA}

Bal-Coelho, B.; Tiessen, H.; Stewart, J. W. B.; Salcedo, I. H.; Sampaio, E. V. S. B. Residue management effects on sugarcane yield and soil properties in Northeastern Brazil. Agronomy Journal, Madison, v.85, n.5, p.1004-1008, 1993.

Brewer, R. Fabric and mineral analysis of soils. New York: John Wiley, 1976. 482p.

Bullock, P.; Fedoroff, N.; Jongerius, A.; Stoops, G.; Tursina, T.; Babel, U. Handbook for soil thin section description. Albrington: Waine Reserch,1985. 152p.

Cabeda, M. S. V. Degradação física e erosão do solo. In: Simpósio de manejo do solo e plantio direto no Sul do Brasil, 3, 1984, Passo Fundo. Anais... Passo Fundo: Univerdidade de Passo Fundo,1984. p.28-33.

Cabrera-Martinez, F.; Harris, W. G.; Carlisle, V. W.; Collins, M. E. Partitioning of clay-sized minerals in coastal plains soils with sandy/loamy boundaries. Soil Science Society America Journal, Madison, v.53, n.5, p.1584-1587, 1989.

Carpenedo, V.; Mielniczuk, J. Estado de agregação e qualidade de agregados de Latossolos Roxos, submetidos a diferentes sistemas de manejo. Revista Brasileira de Ciência do Solo, Campinas, v.14, n.1, p.99-105, 1990.

Chartres, C. J.; Norton, L. D. Micromorphological and chemical properties of Australian soils with hardsetting and duric horizons. Development Soil Science, Amsterdam, v.22, n.4, p.825834, 1994.

Cockroft, B.; Barley, K. P.; Greacen, E. L. The penetration of clays by fine probes and root tips. Australian Journal of Soil Research, Melbourne, v.7, n.2, p.333-348, 1969.

Corsini, P. C.; Malheiros, E. B.; Sachi. E. Sistemas de cultivo da cultura da cana-de-açúcar: efeitos na retenção de água e na porosidade do solo. Revista Brasileira de Ciência do Solo, Campinas, v.10, n.1, p.71-74, 1986.

D’agostini, L. R. Variações temporais da coesividade entre agregados de solo. Porto Alegre: UFRGS, 1992. 82p. Tese Doutorado

Dantas, J. A.; Santos, M. C.; Heck, R. J. Caracterização de podzólicos amarelos irrigados e não irrigados do submédio São Francisco. Revista Brasileira de Ciência do Solo, Viçosa, v.22, n.4, p.761-771, 1998.

Dexter, A. R. Advances in characterization of soil structure. Soil \& Tillage Research, Amsterdam, v.11, n.3, p.199-238, 1988.

Drees, L. R.; Karathanasis, A. D.; Wilding, L. P.; Blevins, R. L. Micromorphological characteristics of long-term no-till and conventionally tilled soils. Soil Science Society America Journal, Madison, v.58, n.3, p.508-517, 1994.

Fitzpatrick, E. A. The micromorphology of soil. Aberdeen: Department of Soil Science of the University of Aberdeen, 1984. 433p.

Helalia, A. M.; Letey, J.; Graham, R. C. Crust formation and clay migration effects on infiltration rate. Soil Science Society America Journal, Madison, v.52, n.1, p.251255, 1988.
Hill, R. L.; Meza-Montalvo, M. Long-term wheel traffic effects on soil physical properties under different tillage systems. Soil Science Society America Journal, Madison, v.54, n.4, p.865870, 1990.

Jacomine, P. K. T.; Cavalcanti, A. C.; Pessoa, S. C. P.; Silveira, C. O. Levantamento exploratório, reconhecimento de solos de Estado de Alagoas. Recife: EMBRAPA/Centro de Pesquisas Pedológicas: SUDENE-DRN, 1975. 531p. Boletim Técnico, 35

Jongerius, A.; Heintzberger, G. The preparation of mammoth-sized thin sections. Wageninger: Soil Survey Institute, 1963. p.337. Soil Survey Paper, 1

Lebert, M.; Horn, T. A method to predict the mechanical strength of agricultural soils. Soil \& Tillage Research, Amsterdan, v.19, n.2, p.275-286, 1991.

Marsili, A.; Servadio, P.; Pagliai, M.; Vignozzi, N. Changes of some physical properties of a clay soil following passage of rubber-and metal-tracked tractors. Soil \& Tillage Research, Amsterdam, v.49, n.2, p.185-199, 1998.

Murphy, C. P. Thin section preparation of soil and sediments. Beskhamsted, Herts: Academic Publishers, 1986. 149p.

Nimer, E. Climatologia do Brasil. 2.ed. Rio de Janeiro: IBGEDERNA, Departamento de Recursos Naturais e Estudos Ambientais,1989. 422p.

Oliveira, C. V.; Ker, J. C.; Duarte, M. N.; Curi, N.; Fontes, L. E. F.Atributos micromorfológicos de solo do projeto Jaíba, norte de Minas Gerais. Revista Brasileira de Ciência do Solo, Viçosa, v.24, n.1, p.117-128, 2000.

Pagliai, M. Micromorphometric and micromorphological investigation on the effect of compaction by pressures and deformations resulting from tillage and wheel traffic. In: Monnier, G.; Goss, M. J. (Ed.) Compaction and Regeneration. Rotterdam: Academic Publishers, 1987. p.31-38.

Silva, A. J. N. Alterações físicas e químicas de um Argissolo Amarelo Coeso sob diferentes sistemas de manejo com cana-de-açúcar. Porto Alegre: UFRS, 2003. 120p. Tese Doutorado

Silva, A. J. N.; Ribeiro, M. R.; Mermut, A. R.; Benke, M. B. Influência do cultivo contínuo da cana-de-açúcar em Latossolos Amarelos coesos do Estado de Alagoas: propriedades micromorfológicas. Revista Brasileira de Ciência do Solo, Viçosa, v.22, n.3, p.515-525, 1998.

Silva, M. S. L.; Ribeiro, M. R. Influência do cultivo contínuo da cana-de-açúcar em propriedades morfológicas e físicas de solos argilosos de tabuleiros do Estado de Alagoas. Revista Brasileira de Ciência do Solo, Campinas, v.16, n.3, p.397-402, 1992.

Tisdall, J. M.; Oades, J. M. Organic matter and water-stable aggregates in soils. Journal of Soil Science, Oxford, v.33, n.2, p.141-163, 1982.

Utomo, W. H.; Dexter, A. R. Age hardening of agricultural top soils. Journal of Soil Science, London, v.32, n.3, p.335-350, 1981.

Vandenbygaart, A. J.; Protz, R.; Tomlin, A. D.; Miller, J. J. Tillage system effects on near-surface soil morphology: observations from the landscape to micro-scale in silt loam soils of southwestern Ontario. Soil \& Tillage Research, Amsterdam, v.51, n.2, p.139-149, 1999. 